\title{
El mito del soldado en el cine
}

\author{
Nataly GuZMán Velasco \\ Departamento de Comunicaciones y Cultura
}

¿Qué es lo especifico del mito? Es transformar un sentido en forma.

Dicho de otro modo, el mito es siempre un robo de lenguaje.

Roland Barthes, en "Mitologías".

Muchos piensan que la cultura de masas está llena de mensajes tan simplificados y tan livianos que no vale la pena considerarlos para un análisis detallado, pues son evidentes. Pero el problema de esta concepción es que precisamente por la existencia de los mensajes simplificados es que en la vida cotidiana de muchas personas estos son los discursos que más han logrado moldear su visión de mundo. Por ello, en este estudio se pretende identificar cuáles son las representaciones sobre la defensa de los valores patrios, la democracia y la libertad, entre otros, que predominan en la caracterización del soldado en las películas sobre las guerras.

Algunos productos cinematográficos resaltan la gloria de los valores patrióticos defendidos en el contexto de una guerra, y es desde el ámbito de la cultura de masas que estos productos se difunden desde una perspectiva predominantemente emotiva y subjetiva que, a la vez, se apega a los discursos oficiales que explican las invasiones y los enfrentamientos. Lo importante es detectar las caracterizaciones, las narrativas y las representaciones que acompañan a estos discursos que promueven una sola forma de vida y una sola visión de los hechos que casi siempre esta contextualizada de manera superficial. Aquí también se hará referencia a las caracterizaciones que acompañan a productos cinematográficos más abiertos en su simbología, pero las notas características elementales de este trabajo se centrarán en el discurso fílmico que promueve una visión unidireccional de los hechos y de las situaciones.

Si se da por sentado que sólo lo que se ve es lo que existe, como parece plantear el "efecto CNN", se estaría de alguna manera despojando a la realidad de sus aspectos más fundamentales de contextualización e interpretación de los hechos solo porque parecen "cotidianos" o sólo porque "suceden" y se mediatizan. ¿Qué tipo de relaciones de poder plantean estos productos cinematográficos insertos en la cultura de masas? ¿Qué caracterizaciones del soldado, entendido como la imagen del espíritu de defensa de la 
identidad nacional de los pueblos y de la libertad, se plantean en los discursos cinematográficos? ¿Qué valores se condenan desde esta perspectiva del culto al sacrificio y del mito de la violencia por la paz? Es importante indagar sobre estos temas no tanto para tener clara la construcción aislada de un discurso, sino para entender como se naturalizan tales construcciones discursivas.
Hay una intrincada red de elementos subjetivos que intervienen en los procesos culturales de apropiación de la realidad individual y colectiva. Los medios de difusión, y en este caso particular, el medio cinematográfico juega un papel importante en la estructuración, la reproducción y la difusión de tales elementos subjetivos. Estos, a su vez, construyen una manera de ver el mundo en la que confluyen poderes diversos pero unidireccionales e irónicamente abarcadores de diferentes ámbitos de la cultura, la inter-subjetividad y la vida cotidiana.

En la década de los años cuarenta hubo tres tendencias importantes. La primera tiene que ver con la línea de películas sobre la Segunda Guerra Mundial. Estas exaltaban la figura del piloto y del soldado que perseveraba en el cumplimento de las órdenes que le habían sido asignadas. La segunda tendencia está ligada a los filmes que retrataban no la gloria, sino la tragedia de "regresar a casa" y encontrarse mutilado, sin empleo, sin capacidad de integrarse a la sociedad. Y la tercera, asociada a las películas que seguían el estilo del filme noir, y que planteaban el desencanto del hombre ante una sociedad fría, individualista y violenta.

En los años cincuenta muchas películas recreaban con nostalgia el orgullo de los soldados obedientes con una arraigada visión de patriotismo triunfalista; hombres que ponían su carrera por encima de su vida personal y la posibilidad de tener su propia familia (De aquí a la eternidad, 1954). Mientras que en los años sesenta, los cineastas de tono más independiente, para los estándares de la época, como Stanley Kubrick, abordaban el tema de la guerra fría desde una perspectiva crítica e irónica, como en el caso de Dr. Strangelove (1964), film que pone de manifiesto el absurdo de la guerra y que cuestiona la madurez intelectual de aquellos que apoyan los enfrentamientos. 
En los setenta y los ochenta en el cine predominaron las sagas fantásticas, como La guerra de las galaxias (1977) e Indiana Jones y los cazadores del arca perdida" (1982). Sin embargo, el cansancio de vivir en una realidad que se podía cuestionar desde diversos ángulos, Ilevó de alguna manera a que continuara la exhibición de películas un tanto más críticas del ejército, más analíticas de la mente, del alma y del comportamiento humano, y más descriptivas sobre los horrores de las guerras más allá del simple elemento gráfico, como Chaqueta metálica, de 1987. Sin embargo, en la década de los noventa, se despierta una nueva serie de películas sobre patriotismo y nostalgia por el soldado que sacrifica su vida por la defensa de la libertad (como en el caso de Salvando al soldado Ryan, 1998).

\section{Las representaciones de los valores paternalistas}

"La verdad no se opone a la falsedad, sino a lo que es más verdadero que la verdad: la simulación".

Jean Baudrillard

La cultura de la defensa de la patria en el cine comercial se caracteriza sobre todo por la constante reiteración de un sistema de símbolos que exaltan su propia versión de la dignidad humana. La guerra, para este caso específico, es planteada como el mecanismo que abre la posibilidad de recuperar la paz. El valor de la libertad se despliega a través de diferentes símbolos y estos configuran en su conjunto una representación general de realidades en conflicto.

Los símbolos de la estética paternalista que predominan en las películas de guerra son: banderas ondeantes al ritmo de una sinfonía épica, que representan al territorio, a la familia y el alma que muere por la libertad de su patria; las autoridades que comandan las misiones, cuyas órdenes no deben desobedecerse y que representan al padre, al jefe del hogar que muestra el camino a seguir; el soldado, que representa el sacrificio de una generación dispuesta a dar la vida en la batalla; la guerra, que "personifica" elemento interruptor de la paz, la prueba que hay que superar para valorar a la familia y a la tierra; la misión, las vidas individuales y colectivas que hay que proteger a cualquier costo. Juntos, estos elementos conforman un núcleo familiar-institucional simbólico en un ámbito formal de comunicación, pero que funciona porque involucra motivaciones subjetivas de lealtad, servicio, sacrificio, disciplina y obediencia.

Desde el discurso cinematográfico predominante, la cultura que glorifica el heroísmo comienza en el hogar, y los superiores se retratan 
como aquellos que dan las órdenes más severas, pero que, como un padre, lo hacen por el bien de sus hijos. Si acaso existiera alguien que intentara aprovecharse de su rango para ser extremadamente autoritario, de alguna manera sus subordinados no se prestarán a su juego. La tendencia general es que los superiores en la cadena de mando sean la personificación de la sabiduría, una sabiduría con el rigor que da la experiencia.

Pero quienes comandan una misión tienen que pagar un precio muy alto para sobrevivir con dignidad. En Rescatando al soldado Ryan (1998) el teniente Miller tiene un tic nervioso. Su mano derecha le tiembla a raíz del estrés con el que tiene que lidiar en el campo de batalla. En Windtalkers (2002), el oficial Enders padece de sordera y de falta de equilibrio, pues en un combate le dispararon en el oído. En Lágrimas del sol (2003), el oficial Waters es un amargado veterano de carácter severamente endurecido por la crudeza de las guerras en las que ha participado. Aún así, estos líderes son ejemplo de autoridad y de sacrificio al mismo tiempo, porque han sufrido consecuencias que de manera tolerante enfrentan para seguir adelante. La compensación es el respeto ganado a pulso que les profesan sus subordinados, incluso los más rebeldes o inconformistas.

El soldado, por su parte, es a la vez el hijo que debe obedecer a esa autoridad sin cuestionar abiertamente sus órdenes, aunque no esté completamente satisfecho con las misiones que le son encomendadas. En la relación autoridad-soldado los vínculos son distantes y las brechas generacionales notorias, pero hay un nexo de admiración mutua y discreta cuando los oficiales de alto rango son honestos: los soldados admiran a sus superiores y este aprecio se hace patente en el cumplimiento de la orden; las autoridades admiran a los soldados por su coraje y tratan de guiarlos como se orienta a un hijo en el que se confía puede con las responsabilidades de un hombre. El soldado personifica en el cine el riesgo, la iniciativa y la diligencia, aún en las peores circunstancias.

Entre ellos, pese a sus diferencias, los soldados son como hermanos. Las películas que manejan un discurso oficial siempre tratan de presentar un grupo de soldados racial y culturalmente diverso que aprende a integrarse en la vicisitud de la guerra. A lo largo de esta relación de "hermanos", el soldado aprende a convivir, a conocer a su prójimo, y aunque luche por mantener su individualidad y sus perspectivas propias de la vida, entiende que son un grupo y que debe cuidar del "otro".

Para darle a las situaciones conflictivas un tinte de "realismo" y una dosis de imperfección, este tipo de filmes siempre introducen a un soldado con actitudes violentas, de un carácter distinto al de los 
demás. Sin embargo, en este punto la situación queda completamente justificada con una explicación sugerida de su conducta. En Salvando al soldado Ryan, Jackson es el miembro violento de la tropa y antes de dispararle al enemigo irónicamente reza y se encomienda a Dios, sin embargo, a pesar de su violencia, la película da a entender que él es quien más vidas de sus compañeros ha salvado. En Windtalkers, un sumiso soldado de origen navajo, se anima a dispararle al enemigo cuando se traumatiza por el asesinato de otro sujeto de su misma raza, pero al final recupera su cordura inicial conmovido por la muerte del oficial blanco que le salvó la vida. El acto de sacrificio aquí retoma una concepción religiosa, en tanto que santifica a quien da su vida en el combate, y en tanto que bendice la existencia del que vive como una nueva oportunidad para retomar su existencia en sociedad y hacer que todo el "sacrificio" haya valido la pena.

El conflicto político que provoca la guerra es representado como un examen de dignidad, en la que el soldado no sólo debe mostrar coraje para hacerse de valor y matar al enemigo, sino también la compasión y el respeto hacia los civiles que encuentra a su paso. En el discurso oficial de las películas de guerra no se discute el conflicto, no se revelan mayores referentes históricos sobre qué es lo que está sucediendo en el mundo en ese momento. Simplemente se retratan los ataques y las reacciones, como mecanismos para mantenerse a flote en el juego.

Las representaciones más fuertes están en la convergencia de las situaciones planteadas. Por ello, la interacción de estos elementos puede ejemplificarse de diferentes maneras a partir de los materiales cinematográficos analizados. En el filme Salvando al soldado Ryan, las autoridades ordenan a un batallón moverse del lugar que tenían asignado para modificar su misión. Ahora tienen que encontrar a un joven soldado perdido en Europa durante la Segunda Guerra Mundial y devolverlo a su casa. Todos los hermanos del soldado, quien se apellida Ryan, han muerto en combate y él es el único sobreviviente, por ello las autoridades parecen estar conmovidas por la situación de la madre de los jóvenes.

Con estos elementos se trata de plantear que la lucha en las guerras no solo tiene que ver con los territorios o los intereses políticos, sino con los valores de la familia. También se quiere indicar que las autoridades no son un grupo de fríos estrategas, sino hombres y mujeres que se identifican con sus semejantes, y que son capaces de cambiar el curso del ejercicio bélico de un batallón con tal de devolverle el consuelo a una madre. La tropa asignada con la misión de encontrarlo se muestra reticente a desviar sus planes, pero obedecen porque es una orden. Hay múltiples cuestionamientos sobre 
qué tan válido es dejar que mueran varios hombres sólo para encontrar a uno, pero a lo largo del camino los soldados van comprendiendo que un hombre "debe hacer lo que debe hacer" $^{\prime \prime}$, algo que no se entiende bien, pero que se siente que es lo correcto. El soldado Ryan representa a un joven dispuesto a luchar por sus nuevos hermanos (los soldados); consciente del dolor de su madre, pero dispuesto a dar la vida por la felicidad de otras madres.

\section{La perspectiva cinematográfica crítica de las versiones oficiales}

Gentlemen, you can't fight in here.

This is the War Room!

Dr. Strangelove. Stanley Kubrick, 1964.

Así como la cultura fílmica comercial ha construido en la mayoría de los casos una cierta mitificación del soldado y ha justificado la defensa de la paz a través de la guerra, así también hay productos cinematográficos que si bien no intentan necesariamente desmitificar tal percepción sí muestran con mayores matices de realismo la situación del soldado, su proceso de institucionalización y su vida en la guerra. Por otra parte, también se pueden encontrar películas que satirizan toda la solemnidad con la que tradicionalmente se pretende identificar a este tipo de temáticas.

\section{Tendencias básicas sobre las diferencias de las construcciones y representaciones cinematográficas del soldado}

\begin{tabular}{|l|l|l|}
\hline \multicolumn{1}{|c|}{ Categorías } & \multicolumn{1}{c|}{ Visión Comercial - Tradicional } & \multicolumn{1}{c|}{ Visión Independiente } \\
\hline Trama & Predeterminada, estandarizada & Imprevisible, inventiva \\
\hline Sujetos & Héroes & Antihéroes \\
\hline Perspectiva & Acrítica & Crítica \\
\hline Personajes & Estereotipos & Personajes de carácter y matices \\
\hline Estrategias & Efectos especiales & Lenguaje: diálogos creativos y juegos de sentido \\
\hline Enemigo & El otro & Uno mismo \\
\hline Mensajes & Repetitivos & Diversos \\
\hline Figuras & Arquetípicas & Atípicas \\
\hline Símbolos & Unidireccionales & Multidimensionales \\
\hline
\end{tabular}

Fuente: Elaboración propia.

Esta propuesta audiovisual más crítica e imprevisible puede ya sea ridiculizar los estereotipos de la figura de autoridad, como en el caso 
de Dr. Strangelove (1964), o puede presentar con mayor detalle las dificultades de la vida en el ejército, como en Chaqueta metálica (1987). En las películas tradicionales sobre guerra ya hay más o menos una dinámica conocida por el público, una dinámica que sin embargo está maquillada con el horror de la muerte en los campos de batalla. Mientras que las visiones más críticas permiten que el receptor se vaya sorprendiendo según como los sucesos se vayan desarrollando, y de la pretensión por la unificación de las aspiraciones colectivas se pasa al cuestionamiento sobre la validez de tales aspiraciones.

En Chaqueta metálica la trama central no es el honor y el triunfalismo de la guerra a pesar de la muerte, sino la angustia que provoca la metamorfosis del hombre en soldado en un régimen autoritario, el enfrentamiento con un territorio desconocido, y la dualidad del ser como enviado de la muerte y enviado de la paz. Esta película no solo retrata un régimen riguroso y exigente, sino un régimen que, en contraste con las cintas más tradicionalistas, de padre pasa a ser un padrastro extremadamente autoritario de los soldados. El tipo de autoritarismo representado por esta película reduce la autoestima y la confianza de los soldados, aunque con el tiempo la mayoría se va adecuando al sistema; sin embargo, a otros los lleva a la depresión, después a la locura y por último al suicidio y al asesinato aún y antes de probar la sangre de los campos de guerra.

Las temáticas planteadas en Chaqueta metálica se centran más en el proceso de deshumanización y de adecuación a la guerra. Sin embargo, de acuerdo con el protagonista principal, decir que uno está "nacido para matar" y que en su corazón lleva "amor y paz" básicamente no es una contradicción, sino un planteamiento sobre la dualidad del hombre. De forma distinta, en Dr. Strangelove, los soldados son representados como un grupo de personas ni necesariamente inteligentes ni necesariamente sensibles.

En Dr. Strangelove, el eslogan de los soldados que se muestra en pantalla es "Dispare primero y pregunte después". Todos se encuentran una base militar donde se están atacando entre ellos mismos, pues confunden a los camiones de refuerzos con los enemigos. La acción se desarrolla en medio de este combate doméstico y al fondo puede distinguirse un rótulo que dice "La paz es nuestra profesión". Dentro de los aviones aparecen unos soldados vistiendo toda la gloria de sus uniformes, pero en pleno ocio escuchando música y jugando cartas. Al mismo tiempo, aparece un presidente que no sabe qué hacer a pesar de todo el poder, de todos los subordinados y de toda la tecnología que lo rodea. 
En síntesis, todas las representaciones sobre la cultura del triunfalismo que se consigue a través de la gloria y el honor de la guerra se plantean cinematográficamente de manera repetitiva, predecible y ambigua; pero en última instancia son productos cinematográficos creados para la conservación de un determinado sistema de valores que no permite cuestionamientos. Por otra parte, las construcciones narrativas que son alternativas a las historias oficiales existen, pero a pesar de su riqueza visual y de lenguaje no tienen ni el alcance ni el nivel de difusión masiva de los productos comerciales. Esto sucede principalmente en Latinoamérica, donde la oferta cultural mediática no siempre es variada.
De acuerdo con los planteamientos revisados sobre la representación de las guerras, la visión tradicional plantea que el ir a la guerra y atacar al enemigo es símbolo de valentía; y que oponerse la guerra nos hace cobardes y desagradecidos con la patria. Esta representación rechaza alternativas de análisis y decisión, no permite sopesar consecuencias o evaluar riesgos. La solidaridad no es un simple apoyo de las visiones de otro, sino un proceso permanente de construcción, negociación e intercambio de significados. Totalmente lo opuesto a los mensajes prefabricados e instantáneos de las películas comerciales tradicionales que abordan las situaciones bélicas, donde la conquista y el triunfo son las únicas formas de orden y estabilidad.

\section{Referencias bibliograficas}

os Boaventura de Sousa Santos. La crítica de la razón indolente. Contra el desperdicio de la experiencia. Volumen I, Para un nuevo sentido común: la ciencia, el derecho y la política en la transición paradigmática. Editorial Desclée de Brouwer S.A. Bilbao, 2003.

os Umberto Eco. Apocalípticos e integrados. Editorial Lumen S.A. Barcelona, 1990.

os Roland Barthes. Mitologías. Editorial Siglo Veintiuno. México, 1989.

os Stuart Hall (editor). Representation. Cultural representations and signifying practices. Sage Publications Ltd. Londres, 1997.

os Pierre Bourdieu. ¿Qué significa hablar? Economía de los intercambios lingüísticos. Madrid, 1988.

\section{Notas}

1 En inglés se usa con frecuencia la frase "A man's gotta do what a man's gotta do". 